\title{
Development of a simple tool for diagnosis and initial approach to hypertension and pre-hypertension in children and youth
}

\author{
Silviu Grisaru ${ }^{1,2}$, Kay Watson-Jarvis ${ }^{1}$, Catherine M. McKenna ${ }^{3}$, Josephine Ho ${ }^{1,4}$, Joyce R. Harder ${ }^{1,5}$, \\ Rebecca A. Trussell ${ }^{1,4}$ \\ ${ }^{1}$ Alberta Children's Hospital, Alberta Health Services, Calgary, Canada \\ ${ }^{2}$ Division of Pediatric Nephrology, Department of Pediatrics, University of Calgary, Calgary, Canada \\ ${ }^{3}$ Department of Family Medicine, University of Calgary, Calgary, Canada \\ ${ }^{4}$ Division of Pediatric Endocrinology, Department of Pediatrics, University of Calgary, Calgary, Canada \\ ${ }^{5}$ Division of Pediatric Cardiology, Department of Pediatrics, University of Calgary, Calgary, Canada \\ Email: sgrisaru@ucalgary.ca
}

Received 17 January 2012; revised 29 March 2012; accepted 10 April 2012

\begin{abstract}
Background: Hypertension and pre-hypertension in children and adolescents are frequently missed despite current screening recommendations and the potential benefit for early diagnosis and intervention. Difficulty in interpretation of office blood pressure readings in children has been partially blamed for the significant under-diagnosis of childhood hypertension. The objective of our group was to develop and evaluate a simple tool designed to assist primary health care physicians to interpret office blood pressure readings in children and adolescents. Methods: A multi-disciplinary advisory group in our institution undertook the development of a diagnostic tool based on currently accepted gold standard parameters. Input from Family Physicians and Pediatricians was used in the design process. The tool was then distributed among Family Physicians in our catchment area and evaluated with a post-distribution survey. Results: A laminated one page summary of pediatric blood pressure parameters and initial approach to pediatric hypertension was created and distributed. Feedback from primary care physicians was mostly positive and supportive of this initiative. Conclusions: Innovating and simplifying the screening process for hypertension and pre-hypertension in childhood may promote early detection and intervention however the effect of such initiatives on the rate of diagnosis of pediatric hypertension will need to be tested prospectively by appropriately designed studies.
\end{abstract}

Keywords: Hypertension; Child; Youth; Diagnostic Tool; Screening

\section{INTRODUCTION}

Hypertension affects almost one in four adults and its prevalence continues to rise $[1,2]$. It is recognized as a leading cause for cardiovascular disease, cerebrovascular accidents and end-stage renal disease [3-5]. Hypertension and its resultant complications do occur in childhood and it is becoming increasingly clear that idiopathic or essential hypertension, which is the most common type of adult hypertension, has its origins in childhood [6]. The prevalence of hypertension in children and youth is on the rise and it has been shown that children who have high blood pressure (BP) tend to become hypertensive adults [7].

Current recommendations suggest that all children $\geq 3$ years of age should have their BP measured at each health care visit [8]. Despite this, as many as $75 \%$ of cases of hypertension and $90 \%$ of cases of pre-hypertension in children and adolescents are undiagnosed [9]. A recent retrospective cross-sectional study of clinic visits for children 3 to 20 years of age at a large urban, pediatric primary care centre found that in $39 \%$ of the visits the blood pressure measurement was above the $95^{\text {th }}$ percenttile, yet in $87 \%$ of the cases the elevated blood pressure reading was not recognized [10].

Difficulties in obtaining accurate BP readings in children due to unavailability of proper sized cuffs or lack of cooperation of younger patients are frequently blamed for hypertension under-diagnosis in childhood [11]. However an additional possible hurdle in performing a quick and efficient office screening of BP in children lies with the complex steps involved in the process of interpreting BP values in children and youth [10]. References for normal childhood BP values have been developed by the Task Force on High Blood Pressure in Children and 
Adolescents; the latest update was published in 2004 [8]. The reference standards consist of two rather complex tables for boys and girls detailing the percentiles of BP for specific ages and height percentiles. Each one of these tables is two pages long and includes more than 1000 different values [8]. Interpretation of a blood pressure reading in a child requires knowledge of the height percentile as well as availability of the BP standards tables. A need for innovative strategies to assist busy primary health care providers in screening children for elevated BP has been suggested [10,12].

This need was also identified during deliberations of our local childhood obesity advisory committee. This led to an initiative to create a simple tool to assist primary care providers in our community to identify and approach hypertension in children and adolescents. We herein describe the development process, the tool itself, and results of an evaluation of its usefulness.

\section{METHODS}

The "Make it HAPPEN" program is a group, familyfocused healthy lifestyle initiative in our tertiary care pediatric centre, for children and youth 6 to 15 years of age who have a $\mathrm{BMI} \geq 85^{\text {th }}$ percentile for age and gender. The advisory committee to this program is led by a Pediatric Endocrinologist and brings together a community based local Family Physician in addition to a dietician, child life specialist, a nurse and a psychologist.

Since the program targets overweight and obese children, BP screening is part of the enrollment process. A communication is sent to the child/youth's Family Physician at the end of the program advising of both BMI measures and BP screen results, with recommendations for follow-up. The first program evaluation report (March 2007) demonstrated that as many as $23 \%$ of the 108 children enrolled in the program could have been classified as hypertensives and $20 \%$ as pre-hypertensive based on BP readings obtained at the time of their enrolment in the program. The high prevalence of apparent hypertension in this population and the frequency with which families reported not having BP measured at their primary care physician's office led to the following initiative: A Pediatric Nephrologist and a Pediatric Cardiologist were added to the program's advisory board and a session focused on this problem was held. Likely causes for the low rate of childhood BP measurement at primary care physician's offices as well as potential interventions to correct this problem were discussed. During these deliberations the Family Physician in our group expressed her and her colleagues' frustration with the current reference standards for childhood hypertension and the cumbersome process of using these standards in the primary care setup. This observation led our group to initiate the development and evaluation of a simplified tool for identifying children with hypertension or pre-hypertension, a tool which would also provide basic guidelines for the initial approach to hypertension in children and youth.

The starting point was the widely accepted reference standards of the Fourth Report on the Diagnosis, Evaluation, and Treatment of High Blood Pressure in Children and Adolescents [8]. Since our goal was to simplify the use of these reference standards we sought to reduce the amount of information (numbers) in an easy to use format while maintaining the integrity of the classifications. To achieve this goal we provided only the range for the $90^{\text {th }}$ and the $95^{\text {th }}$ BP percentiles for each age and gender leaving out the specific values for each individual height percentiles. The lower end of the provided range represents the BP value for children with the lowest height percentile for their age while the upper end represents the highest height percentile. This presentation makes it easy to quickly identify children and youth with normal BP readings, bellow the low end of the range, irrespective of their height. The tool also suggests that adolescents aged 14 years and older should be considered at least pre-hypertensive if their systolic/diastolic BP value is above $120 / 80 \mathrm{mmHg}$. Current references mention values higher than $120 / 80 \mathrm{mmHg}$ as being less than the $90^{\text {th }}$ percentile for tall adolescents however in view of the current cutoff point for pre-hypertension in adults $(120 / 80 \mathrm{mmHg})$, it should also be applied to adolescents $[13,14]$.

The simplified reference table along with some treatment guidelines and an algorithm for the approach to hypertension (also adapted from The Fourth Report on the Diagnosis, Evaluation, and Treatment of High Blood Pressure in Children and Adolescents [8]) were formatted on $\frac{17}{2} \times 11$ sized paper which was folded as a booklet. This first draft was distributed to 10 Family Physicians attending a local continuing education workshop along with a fax-back questionnaire to gather feedback. Four respondents took time to recommend improvements in readability, layout and format. The final product, a laminated two-sided A4 size document, was approved by each of the advisory committee members and the Chief of Pediatrics in our centre. It was then distributed on behalf of the Department of Pediatrics to Family Physicians and Pediatricians in our community.

A follow-up fax-back questionnaire to evaluate the use of this tool was distributed two months later to the same group of Family Physicians and Pediatricians.

\section{RESULTS}

The simplified reference tool for BP screening in children and youth consisting of a one page laminated document shown in Figures 1(a) and (b) as well as the evaluation 
Blood Pressure Levels

\begin{tabular}{|c|c|c|c|c|c|}
\hline \multicolumn{6}{|c|}{ Range of BP values for $5^{\text {th }}-95^{\text {th }}$ percentile of height } \\
\hline \multirow[t]{2}{*}{ Age } & \multirow{2}{*}{$\begin{array}{c}\text { BP } \\
\text { \%ile }\end{array}$} & \multicolumn{2}{|c|}{ Boys } & \multicolumn{2}{|c|}{ Girls } \\
\hline & & Systolic & Diastolic & Systolic & Diastolic \\
\hline \multirow[t]{2}{*}{3} & 90 & $100-109$ & $59-63$ & $100-106$ & $61-65$ \\
\hline & 95 & $104-113$ & $63-67$ & $104-110$ & $65-69$ \\
\hline \multirow[t]{2}{*}{4} & 90 & $102-111$ & $62-67$ & $101-108$ & $64-68$ \\
\hline & 95 & $106-115$ & $66-71$ & $105-112$ & $68-72$ \\
\hline \multirow[t]{2}{*}{5} & 90 & $104-112$ & $65-70$ & 103-109 & $66-70$ \\
\hline & 95 & $108-116$ & $69-74$ & $107-113$ & $70-74$ \\
\hline \multirow[t]{2}{*}{6} & 90 & $105-113$ & $68-72$ & $104-111$ & $68-72$ \\
\hline & 95 & $109-117$ & $72-76$ & $108-115$ & $72-76$ \\
\hline \multirow[t]{2}{*}{7} & 90 & $106-115$ & $70-74$ & $106-113$ & $69-73$ \\
\hline & 95 & $110-119$ & $74-78$ & 110-116 & $73-77$ \\
\hline \multirow[t]{2}{*}{8} & 90 & $107-116$ & $71-76$ & $108-114$ & $71-74$ \\
\hline & 95 & $111-120$ & $75-80$ & $112-118$ & $75-78$ \\
\hline \multirow[t]{2}{*}{9} & 90 & $109-118$ & $72-77$ & $110-116$ & $72-75$ \\
\hline & 95 & $113-121$ & $76-81$ & $114-120$ & $76-79$ \\
\hline \multirow[t]{2}{*}{10} & 90 & $111-119$ & $73-78$ & $112-118$ & $73-76$ \\
\hline & 95 & $115-123$ & $77-82$ & $116-122$ & $77-80$ \\
\hline \multirow[t]{2}{*}{11} & 90 & $113-121$ & $74-78$ & $114-120$ & $74-77$ \\
\hline & 95 & $117-125$ & $78-82$ & $118-124$ & $78-81$ \\
\hline \multirow[t]{2}{*}{12} & 90 & $115-123$ & $74-79$ & $116-122$ & $75-78$ \\
\hline & 95 & $119-127$ & $78-83$ & $119-126$ & $79-82$ \\
\hline \multirow[t]{2}{*}{13} & 90 & $117-126$ & $74-79$ & $117-124$ & $76-79$ \\
\hline & 95 & $121-130$ & $79-83$ & $121-128$ & $80-83$ \\
\hline
\end{tabular}

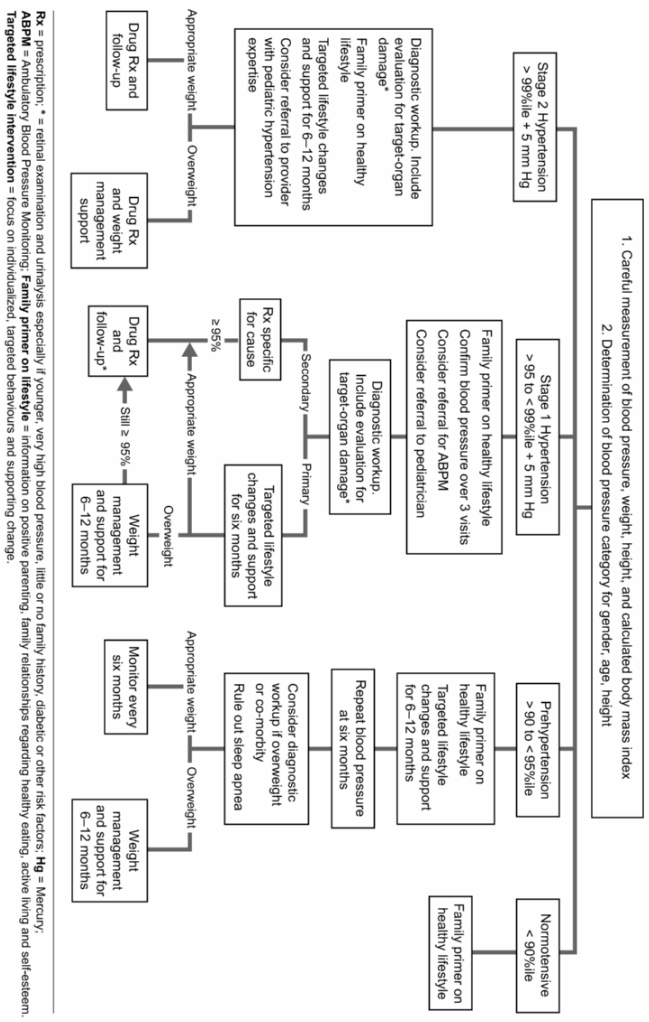

Blood Pressure in Children A Short Guide for Diagnosis and Treatment

- Children $\geq 3$ years of age should have BP measured.

- Auscultation is the preferred method.

- Remember, blood pressure is variable (SBP).

- If a cuff is too small, the next larger cuff is used.

- Accurate height (wall-mounted stadiometer).

- If blood pressure $<95^{\text {th }}$ percentile, confirm 2 times over 12 months If $>95^{\text {th }}$ percentile plus $5 \mathrm{~mm} \mathrm{Hg}$, confirm 2 times over 2 months.

- Severe hypertension ( $>20 \mathrm{~mm} \mathrm{Hg}$ above 95 th \%ile, systolic or diastolic) should be promptly referred to pediatrician for ambulatory blood pressure measurement.

\section{Classifications of Hypertension}

Normal Blood Pressure

SBP and DBP less than the $90^{\text {th }}$ percentile.

Pre-Hypertension

SBP or DBP $\geq 90^{\text {th }}$ percentile but less than $95^{\text {th }}$ percentile. For adolescents, blood pressure levels $\geq 120 / 80 \mathrm{~mm} \mathrm{Hg}$.

Stage 1 and 2 Hypertension

$\mathrm{SBP}$ or DBP from $95^{\text {th }}$ percentile plus $5 \mathrm{~mm} \mathrm{Hg}$ and above.

NOTE: Percentiles are for sex, age, and height for blood pressure measured on at least three separate occasions; if systolic and diastolic fall into different percentiles, categorize by higher value.

$\mathrm{SBP}=$ systolic blood pressure $; \mathrm{DBP}=$ diastolic blood pressure

Adapted with permission from National High Blood Pressure Education Program Working Group on High Blood

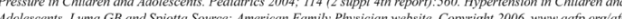

\section{$\square$ Alberta Health Services}

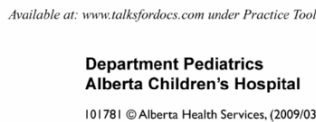

(a)

\section{Treatment}

Normal BP: Recheck at next physical examination. Encourage healthy eating, sleep and regular physical activity.

Health Canada (publications@hc-sc.gc.ca; www.healthcanada.ca)

- Eating Well with Canada's Food Guide.

- Physical Activity Guide 6-9; Magazine for Children 6-9; Family Guide for 6-9.

- Activity Guide for Youth; Magazine for Youth 10-14; Family Guide for 10-14.

Alberta (www.healthyalberta.ca)

- Healthy Eating and Active Living 1-5, 6-12, 13-18 years.

Pre-Hypertension: Recheck within 6 months. Lifestyle counselling for parents and child/youth; focus on parents if young child. If at risk for overweight ( $>85 \%$ ile BMI for age and gender), goal is to improve weight for height over time through strategies for healthy eating, daily physical activity and reduction of sedentary lifestyle. Family history of diabetes, cardiovascular diseases or overweight place children at greater risk.

Resources: Make It HAPPEN program (403-955-7190) for families of children $>85^{\text {th }} \%$ ile BMI; community pediatric dietitian; Living Well Program (free for parents who are hypertensive, overweight or have chronic disease).

Stage I or II Hypertension: Recheck in 1-2 weeks or sooner if symptomatic. If elevated on 2 more occasions, evaluate in accordance with reference document $\mathrm{OR}$ refer to pediatrician within 1 month. Also, proceed as in Pre-hypertension.

Resources: Make It HAPPEN program; targeted lifestyle counselling with community pediatric dietitian and weight management strategies if child/youth at risk for overweight, $>85^{\text {th }} \%$ ile BMI and family history (as above)

(b)

Figure 1. (a) Hypertension and pre-hypertension in children and youth-A diagnostic tool; (b) Hypertension and pre-hypertension in children and youth-A diagnostic tool. 
survey was distributed by mail to almost 400 Family Physicians and 54 Pediatricians. A total of 44 faxed responses to the post-distribution survey were received and results are summarized in Table 1. Some respondents added comments none of which were negative. The following are some examples of the provided comments: "The tool increased my awareness to hypertension in children", "I keep the tool in my exam room for quick and easy reference", "It helps to quickly confirm normality of BP and lets me know if I should recheck". One Family Physician indicated willingness to participate in the next revision of the tool, "to further simplify it".

\section{DISCUSSION}

The importance of early diagnosis and treatment of hypertension and pre-hypertension is well accepted and uncontested [15]. Facilitating screening for hypertension in children and youth should be a priority if the goal is to improve current rates of detection of hypertension and pre-hypertension in children and youth, which have been shown to be very low [9]. Development of a simple tool to support early diagnosis in the primary care setup may be one of the needed interventions to achieve this goal.

The observation regarding the need to simplify the current reference standards created by The Fourth Report on the Diagnosis, Evaluation, and Treatment of High Blood Pressure in Children and Adolescents is not exclusive to our group. A somewhat similar attempt to develop a simplified childhood BP reference table has been published in Pediatrics in June 2009 [12], subsequent to our local initiative. However our experience is unique because it started with observations made in the field by practitioners and community Family Physician, the latter of which also provided feedback regarding the utility of this simplified tool aimed at easing the task of screening for hypertension in children and youth. In addition, our tool provides a quick reference on the approach to treatment of children and youth suspected of hypertension or pre-hypertension.

The introduction of this locally developed simplified tool to support detection and initial management of childhood hypertension in our community did not start as a research project but rather a practical measure for an observed need. Consequently our attempt to evaluate this tool had many limitations: convenience bias in the choice of Family Physicians and Pediatricians to whom the tool was distributed, the tool and the post-distribution survey were faxed to practice locations rather than individual physicians and the response rate to the fax survey was very low.

Notwithstanding these important limitations, this is the first description of a simplified tool for detection of pediatric hypertension developed at the request and with the collaboration of primary care physicians. Moreover, this is the first attempt to conduct a qualitative evaluation of such a tool with a survey among primary care physicians who provided mostly positive feedback. Undoubtedly of even higher interest would be a quantitative evaluation of this tool's implementation using outcomes such as a change in the rate of diagnosis of pediatric hypertension and a comparison with the diagnosis rate using the blood pressure tables from the Fourth Report on the Diagnosis, Evaluation and Treatment of High Blood Pressure in children and Adolescents (http://www.nhlbi.nih.gov/guidelines/hypertension/child tbl.htm) [8].

Table 1. Results of a survey among Family Physicians and Pediatricians post-distribution of a childhood hypertension diagnostic tool.

\begin{tabular}{|c|c|c|c|c|}
\hline Question & $\mathrm{n}$ & & Answers & \\
\hline $\begin{array}{l}\text { Do you remember the pediatric blood } \\
\text { pressure screening tool? }\end{array}$ & $\mathrm{n}=44$ & Yes $=22(50 \%)$ & No-12 $(27 \%)$ & Did not receive-10 $(23 \%)$ \\
\hline Did you use the tool? & $\mathrm{n}=22$ & Yes-16(73\%) & No $-6(27 \%)^{*}$ & - \\
\hline If yes, how often do you use this tool? & $\mathrm{n}=15^{\dagger}$ & Daily-3 $(20 \%)$ & Weekly-8 (53\%) & Monthly-4 (27\%) \\
\hline $\begin{array}{l}\text { How helpful is the tool ( } 5 \text { point } \\
\text { scale)? }\end{array}$ & $\mathrm{n}=17^{\ddagger}$ & $\begin{array}{c}\text { Not helpful (1-2)-1 } \\
(6 \%)\end{array}$ & $\begin{array}{c}\text { Somewhat helpful (3) - } 4 \\
(24 \%)\end{array}$ & Helpful $(4-5)-12(71 \%)$ \\
\hline
\end{tabular}


Unfortunately we were not able to evaluate these outcomes as part of this initiative. The incidence and current rate of diagnosis of pediatric hypertension in our community (as in many other communities) is not known. We are striving to obtain support for a follow-up study that would answer these questions and help to further evaluate the usefulness of this pediatric hypertension diagnostic tool. We hope that this current report will help raise awareness and add to the body of evidence supporting prospective well designed studies aimed at improving diagnostic rates of pediatric hypertension.

\section{REFERENCES}

[1] McAlister, F.A., Wooltorton, E. and Campbell, N.R. (2005) The Canadian Hypertension Education Program (CHEP) recommendations: Launching a new series. $\mathrm{Ca}$ nadian Medical Association Journal, 173, 508-509. doi:10.1503/cmaj.050737

[2] Tu, K., Chen, Z. and Lipscombe, L.L. (2008) Prevalence and incidence of hypertension from 1995 to 2005: A population-based study. Canadian Medical Association Journal, 178, 1429-1435. doi:10.1503/cmaj.071283

[3] Pastor-Barriuso, R., Banegas, J.R., Damián, J., Appel, L.J. and Guallar, E. (2003) Systolic blood pressure, diastolic blood pressure, and pulse pressure: An evaluation of their joint effect on mortality. Annals of Internal Medicine, 139, 731-739.

[4] Hebert, P.R., Moser, M., Mayer, J., Glynn, R.J. and Hennekens, C.H. (1993) Recent evidence on drug therapy of mild to moderate hypertension and decreased risk of coronary heart disease. Archives of Internal Medicine, 153, 578-581. doi:10.1001/archinte.1993.00410050018004

[5] Klag, M.J., Whelton, P.K., Randall, B.L., Neaton, J.D., Brancati, F.L., Ford, C.E., Shulman, N.B. and Stamler, J. (1996) Blood pressure and end-stage renal disease in men. New England Journal of Medicine, 334, 13-18. doi:10.1056/NEJM199601043340103

[6] McNiece, K.L., Poffenbarger, T.S., Turner, J.L., Franco, K.D., Sorof, J.M. and Portman, R.J. (2007) Prevalence of hypertension and pre-hypertension among adolescents. Journal of Pediatrics, 150, 640-644.

\section{doi:10.1016/j.jpeds.2007.01.052}

[7] Flynn, J.T. (2010) Pediatric hypertension update. Current Opinion in Nephrology and Hypertension, 19, 292-297. doi:10.1097/MNH.0b013e3283373016

[8] National High Blood Pressure Education Program Working Group on High Blood Pressure in Children and Adolescents (2004) The fourth report on the diagnosis, evaluation, and treatment of high blood pressure in children and adolescents. Pediatrics, 114, 555-576. doi:10.1542/peds.114.2.S2.555

[9] Hansen, M.L., Gunn, P.W. and Kaelber, D.C. (2007) Underdiagnosis of hypertension in children and adolescents. Journal of the American Medical Association, 298, 874-879. doi:10.1001/jama.298.8.874

[10] Brady, T.M., Solomon, B.S., Neu, A.M., Siberry, G.K. and Parekh, R.S. (2010) Patient-, provider-, and cliniclevel predictors of unrecognized elevated blood pressure in children. Pediatrics, 125, e1286-e1293. doi:10.1542/peds.2009-0555

[11] Gomez-Marin, O., Prineas, R.J. and Rastam, L. (1992) Cuff bladder width and blood pressure measurement in children and adolescents. Journal of Hypertension, 10, 1235-1241. doi:10.1097/00004872-199210000-00018

[12] Kaelber, D.C. and Pickett, F. (2009) Simple table to identify children and adolescents needing further evaluation of blood pressure. Pediatrics, 123, e972-e974. doi:10.1542/peds.2008-2680

[13] Collins, R.T. and Alpert, B.S. (2009) Pre-hypertension and hypertension in pediatrics: Don't let the statistics hide the pathology. Journal of Pediatrics, 155, 165-169. doi:10.1016/j.jpeds.2009.02.006

[14] Flynn, J.T. and Falkner, B.E. (2009) Should the current approach to the evaluation and treatment of high blood pressure in children be changed? Journal of Pediatrics, 155, 157-158. doi:10.1016/j.jpeds.2009.03.058

[15] Lurbe, E., Cifkova, R., Cruickshank, J.K., Dillon, M.J., Ferreira, I., Invitti, C., Kuznetsova, T., Laurent, S., Mancia, G., Morales-Olivas, F., Rascher, W., Redon, J., Schaefer, F., Seeman, T., Stergiou, G., Wühl, E., Zanchetti, A. and European Society of Hypertension (2009) Management of high blood pressure in children and adolescents: Recommendations of the European Society of Hypertension. Journal of Hypertension, 27, 1719-1742. doi:10.1097/HJH.0b013e32832f4f6b 